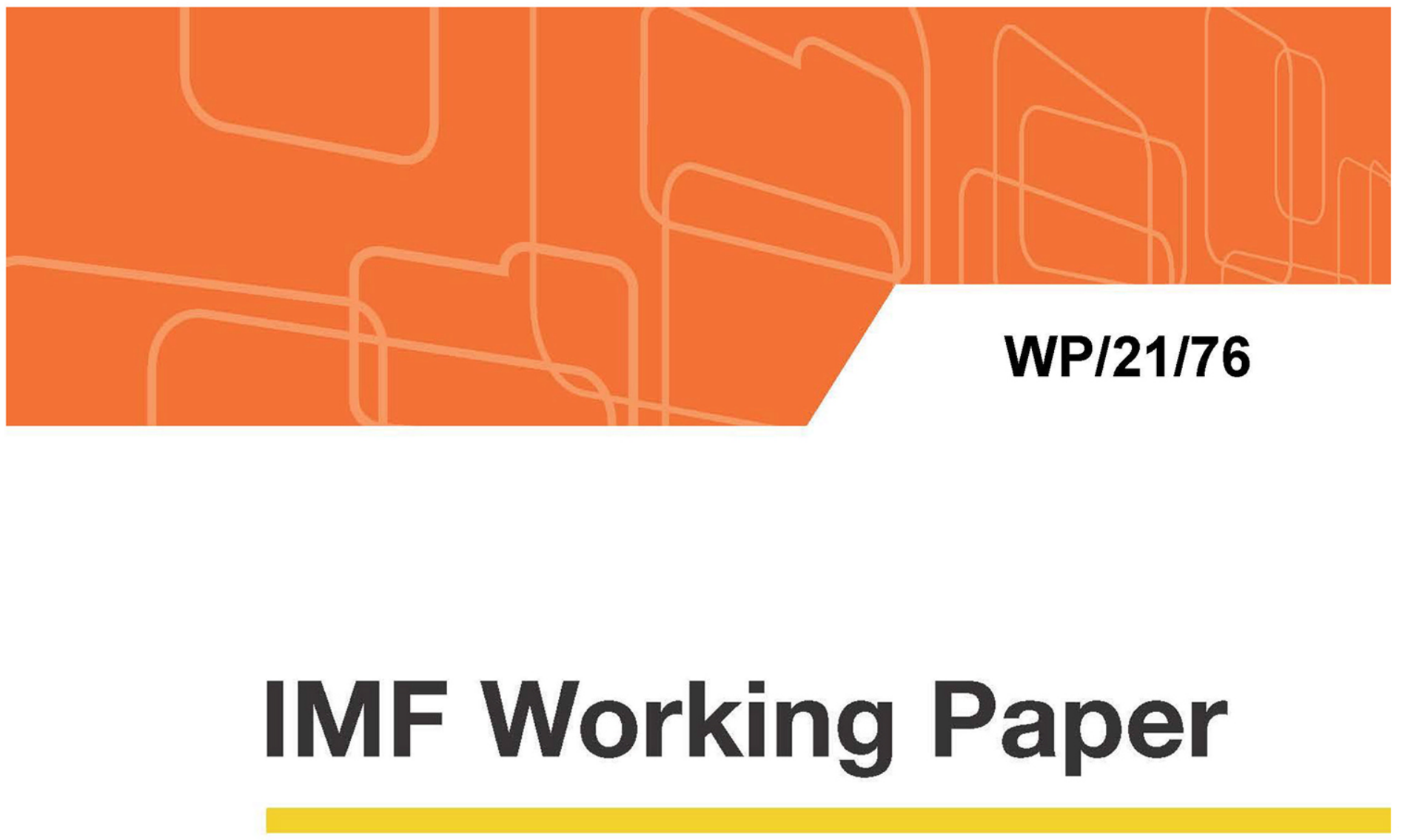

\title{
Uncertainty Premia, Sovereign Default Risk, and State-Contingent Debt
}

by Francisco Roch and Francisco Roldán

IMF Working Papers describe research in progress by the author(s) and are published to elicit comments and to encourage debate. The views expressed in IMF Working Papers are those of the author(s) and do not necessarily represent the views of the IMF, its Executive Board, or IMF management.

I N TER N A T I O N A L M O N E T A R Y F U N D 


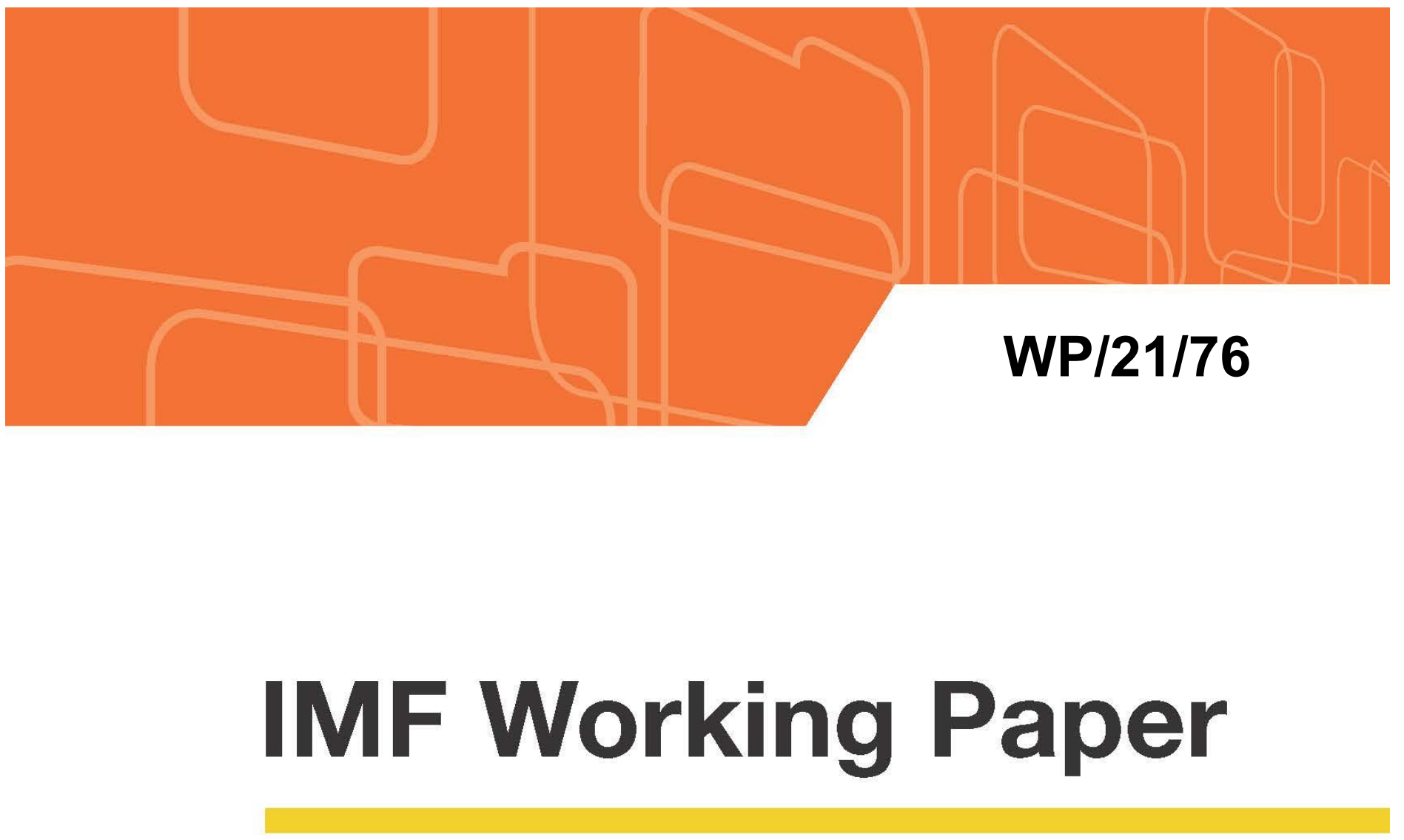

\section{Uncertainty Premia, Sovereign Default Risk, and State-Contingent Debt}

by Francisco Roch and Francisco Roldán

IMF Working Papers describe research in progress by the author(s) and are published to elicit comments and to encourage debate. The views expressed in IMF Working Papers are those of the author(s) and do not necessarily represent the views of the IMF, its Executive Board, or IMF management.

$$
\text { I N T E R N A T I O N A L M O N E T A R Y F U N D }
$$




\title{
IMF Working Paper
}

Research Department

\section{Uncertainty Premia, Sovereign Default Risk, and State-Contingent Debt ${ }^{1}$ Prepared by Francisco Roch and Francisco Roldán}

Authorized for distribution by Deniz Igan

March 2021

\begin{abstract}
IMF Working Papers describe research in progress by the author(s) and are published to elicit comments and to encourage debate. The views expressed in IMF Working Papers are those of the author(s) and do not necessarily represent the views of the IMF, its Executive Board, or IMF management.
\end{abstract}

\begin{abstract}
We analyze how concerns for model misspecification on the part of international lenders affect the desirability of issuing state-contingent debt instruments in a standard sovereign default model à la Eaton and Gersovitz (1981). We show that for the commonly used threshold state-contingent bond structure (e.g., the GDP-linked bond issued by Argentina in 2005), the model with robustness generates ambiguity premia in bond spreads that can explain most of what the literature has labeled as novelty premium. While the government would be better off with this bond when facing rational expectations lenders, this additional source of premia leads to welfare losses when facing robust lenders. Finally, we characterize the optimal design of the statecontingent bond and show how it varies with the level of robustness. Our findings rationalize the little use of these instruments in practice and shed light on their optimal design.
\end{abstract}

JEL Classification Numbers: E43, E44, F34, G12, H63, O16

Keywords: Sovereign debt, default, state-contingent debt instruments, robust control, ambiguity premia

Author's E-Mail Address:froch@imf.org,froldan@imf.org

\footnotetext{
${ }^{1}$ Thanks for insightful discussions to Suman Basu, Martin Beraja, Jaroslav Borovička, Giovanni Dell'Ariccia, Gita Gopinath, Juan Carlos Hatchondo, Deniz Igan, Julian Kozlowski, Leonardo Martinez, Ignacio Presno, Juan Sánchez, Thomas Sargent, Nicholas Trachter, Jeromin Zettelmeyer, and participants at several academic seminars and conferences.
} 


\section{Contents}

1 Introduction $\quad \underline{4}$

2 Some recent experiences with state-contingent debt $\quad \underline{10}$

3 A stylized model of sovereign default with robustness

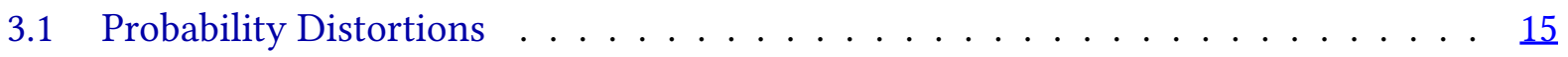

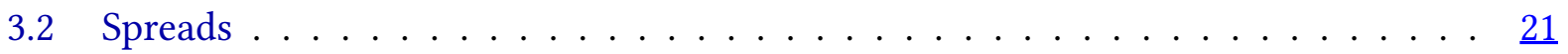

4 The quantitative model $\quad \underline{24}$

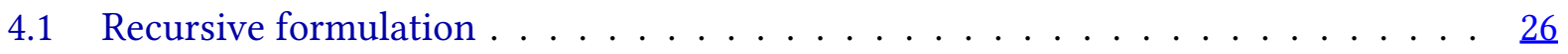

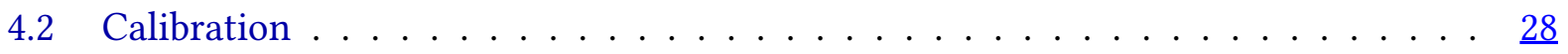

5 Results $\quad \underline{30}$

6 Conclusion $\quad \underline{34}$ 


\section{Introduction}

The recent European sovereign debt crises and the increase in public debt levels after the COVID19 shock have brought proposals for state-contingent debt instruments to the forefront of policy debates as a strategy to avoid costly defaults. ${ }^{1}$ There is also a substantial theoretical literature focusing on the merits of indexing sovereign debt to real variables to help with macroeconomic stabilization and risk sharing. Borensztein and Mauro (2004), Hatchondo and Martinez (2012) and Bertinatto et al. (2017) argue that GDP-indexed bonds could allow governments to reduce both the cyclicality of fiscal policy and default risk while improving risk sharing with international creditors. More generally, the benefits of improving international risk sharing have been discussed extensively since the seminal work by Backus et al. (1992). Several recent studies focusing on the advantages of fiscal unions have found that the gains from improving regional stabilization and risk sharing are quantitatively important (Beraja, 2020; Farhi and Werning, 2017). Statecontingent debt could replicate these features without having to resort to a politically unfeasible combination of taxes and transfers. ${ }^{2}$

Despite these well-understood advantages, the use of state-contingent debt instruments is scarce in practice and countries have not been able to issue such financial instruments at a reasonable premium. ${ }^{3}$ Surprisingly, while some practical implementation challenges have been discussed among policy makers, there is little theoretical analysis investigating them and the lack of indexation in sovereign debt markets remains a puzzle. IMF (2017) and Benford et al. (2018) point to myopia on the part of issuers, who might be out of office before the gains fully materialize. Krugman (1988) argues that GDP-indexed bonds could create moral hazard problems by deincentivizing the government to conduct growth-friendly policies or misreport GDP statistics. However, these arguments do not seem to be empirically relevant. ${ }^{4}$ Others argue that markets

\footnotetext{
${ }^{1}$ See, for instance, United Nations (2006) and IMF (2020).

${ }^{2}$ Beraja (2020) and Farhi and Werning (2017) show that the efficient risk sharing arrangement within a fiscal union could be achieved through a simple contingent transfer rule that bear resemblances to a GDP-indexed bond.

${ }^{3}$ Recent cases include Argentina (2005), Greece (2012) and Ukraine (2015).

${ }^{4}$ This argument should also apply to inflation-linked bonds but many countries have issued these type of securi-
} 
for these instruments tend to be shallow and, thus, these bonds would carry a large liquidity premium. Moretti (2020) investigates this liquidity channel and finds that state-contingent debt is still welfare-improving. Overall, there are no compelling arguments in the literature to outweigh the aforementioned merits of indexation and justify their little use in practice.

This paper aims to fill this gap and proposes a novel mechanism to understand why statecontingent debt has only been issued on a modest scale and severely underpriced. We evaluate state-contingent instruments in light of a sovereign default framework à la Eaton and Gersovitz (1981) with long-term debt, augmented with international lenders who fear model misspecification. In this environment, foreign lenders have doubts about the probability model of the small open economy's exogenous income process and guard themselves against this ambiguity by forming pessimistic expectations. Lenders with preferences for robustness distort probabilities about exogenous shocks in an endogenous way by boosting the probability of low-utility states and seek decision rules that perform well under these worst-case distributions. In the model, low utility events are associated with periods of high default risk and, in the case of state-contingent debt, periods in which stipulated repayments are low.

The presence of robust lenders creates a tradeoff for the optimal design of state-contingent debt as contingency in stipulated repayments can help reduce the probability of default and the volatility of consumption while improving risk sharing with the foreign creditors as in previous studies (e.g., Hatchondo and Martinez, 2012). The typical design of state-contingent instruments that countries have recently used involves a threshold below which no payments are made (e.g., the 2005 Argentina GDP warrant). This structure is sensitive to the types of probability distortions that robust lenders worry about, which leads them to heavily discount the bond. In line with the empirical evidence, our model with robust lenders generates wide spreads for this type of instruments, which also lead to equilibrium welfare losses compared to noncontingent debt.

Robustness is a standard device in the asset-pricing literature which enables more realistic ties. Moreover, the moral hazard problem could also apply to non-contingent debt if the costs of defaults vary with income as is often assumed in the sovereign default literature. 
market prices of risk. In the context of noncontingent debt, Pouzo and Presno (2016) show that augmenting the baseline sovereign default model with robust lenders is essential to simultaneously match the spread dynamics and the frequency of default observed in the data. They also show that the same model with lenders with standard CRRA preferences and no robustness would generate counterfactually high bond prices for plausible levels of risk aversion. Similarly to the equity premium puzzle, for large values of risk aversion the model without robustness can generate high spreads for noncontingent debt at the expense of an extremely low risk-free rate at odds with the data.

One interpretation that motivates this framework is as a way to capture potential concerns that the evolution of the country's GDP (or the underlying variable associated to the statecontingent bond) may be different in the future than the current estimate of what it has been in the past. This could represent fears that the model used to fit the past GDP series may require more data to accurately capture the features of the economy. But it could also represent fears that the process itself may change (among other reasons, if the government implements different, perhaps suboptimal, policies in the future, or because of incentives to misreport GDP or other statistics). Robustness allows the foreign lenders to price in these types of uncertainty around a baseline model. Different degrees of robustness could also capture the degree of credibility that lenders assign to the countries they lend to.

The sovereign default framework à la Eaton and Gersovitz (1981) framework is commonly used for quantitative studies of sovereign debt and has been shown to generate a plausible behavior of sovereign debt and spreads. Formally, we analyze a small open economy that receives stochastic endowments of a single tradable good. The government is benevolent, issues long-term debt in international markets, and cannot commit to repay its debt. While not in default, the government can issue debt which is purchased and priced by competitive foreign lenders. Following Pouzo and Presno (2016), we extend the canonical model by assuming that these foreign lenders are endowed with multiplier preferences (Hansen and Sargent, 2001), a tractable way to introduce 
concerns for robustness. In our baseline model, the government issues noncontingent bonds. By varying the asset structure, we examine the equilibrium consequences of making debt payments linked to the realization of the income shock in different ways.

We structure our discussion around the GDP warrants issued by Argentina as part of its 2005 debt restructuring. Costa, Chamon, and Ricci (2008) find that these bonds traded at a large premia: between 300 and 400bps which they attribute to the default risk of other securities, and a residual of $1200 \mathrm{bps}$ (which declined over time to about 600bps) which they interpret as a premium for 'novelty'. We first calibrate our model to match key moments in the data for Argentina assuming that the government only issues noncontingent debt. Then we evaluate the effects of indexation by assuming the government can issue a state-contingent bond (which we label as 'threshold' bond) that resembles the structure of the GDP warrant issued by Argentina. With rational-expectations lenders, this threshold bond provides welfare gains to the country relative to noncontingent debt. The threshold bond also approximates the structure of optimal state-contingent debt when facing rational-expectations lenders. These gains, however, are overturned with robust lenders, who charge high spreads as their probability distortions magnify the likelihood of states with lower payments -an ambiguity spread. This ambiguity spread explains most of the so-called novelty premium on Argentine GDP warrants.

We then characterize the structure of the optimal state-contingent bond and show how it is affected by the degree of robustness. In contrast to the commonly used threshold bond, the optimal design generates substantial welfare gains, although these gains are decreasing in the level of robustness. For tractability, we first characterize the optimal design of state-contingent debt in a stylized version of our model and investigate how it responds to the lenders' preference for robustness. We show how mean-preserving differences in the structure of promised repayments -which have no impact on rational-expectations, risk-neutral lenders- may imply large differences in the spreads charged by lenders with plausible values of the robustness parameter. The lenders' robustness limits the scope for risk-sharing in particular ways: the optimal debt structure 
features less contingency, lower slopes, and an avoidance of regions with zero or low stipulated repayments. On the one hand, the government would like to minimize the contingency in stipulated repayments in order to prevent probability distortions. But the government also needs to minimize another source of contingency given by default risk ex-post. This tradeoff limits the scope for risk-sharing available to the government. We find that the gains from state-contingent debt are decreasing in the degree of robustness. These insights are preserved in the quantitative version of our model, where for computational reasons we only optimize over a parametric family of state-contingent instruments.

Overall, our findings cast doubts about the desirability of using the type of state-contingent bonds that countries have been issuing in the past and demostrate how the optimal bond indexation depends on the degree of lenders' preferences for robustness. Our model rationalizes the so-called novelty premia in threshold bonds as ambiguity premia associated with the type of contingency these bonds introduce, which translate into substantial welfare losses for the government. Robustness can therefore explain why countries have not issued these types of bonds more often and the harsh discounts at which these bonds have been trading.

Related literature Our analysis builds on and extends three branches of the literature: sovereign default, robust control theory, and the implications of state-contingent debt. First, our study is related to the recent literature on quantitative models of sovereign default that extended the approach developed by Eaton and Gersovitz (1981), starting with Aguiar and Gopinath (2006) and Arellano (2008). Different aspects of sovereign debt dynamics and default have been analyzed in these quantitative studies. Excellent surveys of the literature on sustainable public debt and sovereign default can be found in handbook chapters by Aguiar, Chatterjee, Cole, and Stangebye (2016) and D’Erasmo, Mendoza, and Zhang (2016).

Our study also relates to the literature on robust control methods pioneered by Hansen and Sargent (2016). A growing theoretical macro literature extends canonical models to the case in 
which the social planner and/or private agents fear model misspecification and search for robust policies under worst-case scenarios. Adam and Woodford (2012) introduce robustness in a New Keynesian Model to analyze optimal robust monetary policy. Bidder and Smith (2012) develop an algorithm to apply robust control methods within nonlinear DSGE models, and show that the interaction between time varying risk and robustness provides an amplification mechanism for volatility shocks (which they interpret as animal spirits). Finally, we relate closely to Pouzo and Presno (2016) who study a sovereign default model with robust international lenders in the context of noncontingent debt. Their analysis shows how the introduction of robust lenders improves the quantitative performance of sovereign default models. Robustness helps match bond spreads dynamics observed in the data without resorting to counterfactually high default frequency by historical standards. We then study how international investors' concerns about model misspecification affect the spreads, welfare implications, and optimal design of state-contingent bonds.

Third, our paper relates to the literature that studies the implications of issuing state-contingent debt. Borensztein and Mauro (2004) focus on the implications and benefits of state-contingent debt for the cyclicality of fiscal policy. Durdu (2009) shows that the degree of indexation should be optimally chosen to smooth sudden stops, and that this optimal degree of indexation depends on the persistence and volatility of the shocks an economy faces. More closerly related to our paper, Hatchondo and Martinez (2012) and Bertinatto et al. (2017) study the effects of introducing income-indexed bonds into standard sovereign default models. Both studies find that, in models without robust lenders, GDP-indexed securities support large welfare gains when designed optimally. These papers emphasize that GDP-linked bonds allow the government to eliminate default risk while increasing indebtedness, thereby reducing the equilibrium volatility of consumption relative to income. However, their baseline model with one-period bonds generates counterfactual bond spread dynamics and debt levels. For example, the benchmark calibration in Hatchondo and Martinez (2012) generates a 3\% mean spread and 4\% debt-to-income ratio in their simulations. We build on these papers by clarifying how robustness on the part of lenders 
helps match empirical (low) bond prices which ultimately overturns the conclusions on welfare implications of state-contingent debt.

Layout The remainder of the paper is structured as follows. First, section 2 documents a selected number of recent country experiences with sovereign state-contingent bonds. Section 3 lays out a simple two-period model that illustrates how the optimal design of state-contingent bonds and the associated welfare implications depend on the lenders' preferences for robustness. Section 4 introduces the quantitative model. Section 5 presents the quantitative results. Finally, section 6 concludes.

\section{Some recent experiences with state-contingent debt}

State-contingent debt instruments are not used frequently in sovereign borrowing. We summarize here some recent cases, along with a description of the contingency involved in the various issuances.

Pina (2020) compiles 38 instances of issuances of sovereign state-contingent debt, ranging from the cotton bonds issued by the Confederate States of America in 1863 to the IBRD Cat bonds issued in 2018 by Peru, Colombia, Chile, and Mexico to stipulate lower debt payments in case of earthquakes. The vast majority of bonds are structured in a way that promises reduced or no payments if some measure of output, or a key export price, falls below a certain threshold.

Costa, Chamon, and Ricci (2008) describe in detail the GDP-warrants issued by Argentina as part of its 2005 debt restructuring. This contract was characterized by a threshold and a slope. Payments only occured if the state of the economy satisfied three conditions. First, real GDP growth must exceed 'baseline' GDP growth in the reference year. ${ }^{5}$ Second, the level of real GDP had to be higher than the compounding of the baseline growth rates. Finally, payments only occured if the cumulative amount of past payments was below another threshold (of 48 cents

\footnotetext{
${ }^{5}$ Baseline GDP growth was set by the authorities to gradually converge from an initial level of $4.3 \%$ in 2005 to a long-run level of $3 \%$ at the maturity of the bond in 2034 .
} 
of the currency of denomination per unit of security). If the threshold was satisfied, the slope component of the bond meant that payments were a fraction of the difference between the actual and baseline levels of real GDP.

As was the case with other similar instruments, the Argentinian GDP warrants traded at heavy discounts. Pricing bonds with indexed repayments requires taking expectations and therefore a model for the distribution of the stochastic process upon which the payments are contingent. Costa, Chamon, and Ricci (2008) use Monte Carlo simulations based on historical data to compute theoretical prices for the GDP warrants we are interested in. They find wide spreads: between 300 and 400bps which they attribute to the default risk of other securities, and a residual of $1200 \mathrm{bps}$ (which declined over time to about 600bps) which they interpret as a premium for 'novelty.' As we will see below, our framework with robust lenders is able to generate deep discounts, in line with the empirical evidence. In this sense, we interpret the wide spreads on some types of sovereign state-contingent debt as reflecting ambiguity premia.

\section{A stylized model of sovereign default with robustness}

This section presents a stylized sovereign default model to illustrate the forces at play. A small open economy, populated by a government and a representative agent, faces risk-neutral competitive foreign lenders. The world lasts for two periods in which the government receives endowments $\left(y_{1}, y_{2}\right)>0$. There is uncertainty about two random variables, both of which are realized in the second period: $z$ which determines the value of $y_{2}(z)$ and a utility cost of defaulting $\xi$.

Assets Only one type of security is traded. When the government issues debt, it promises a repayment $R(z)$ in state $z$ of the second period. Different specifications of the stipulated repayment function $R$ represent different types of state-contingent debt structures. We focus on four different types of repayment functions summarized in Table $1 .^{6}$

\footnotetext{
${ }^{6}$ In line with previous studies (Bertinatto et al., 2017; Hatchondo and Martinez, 2012), we evaluate the effects of a total move to state-contingent debt. In reality, different types of bonds might be issued simultaneously.
} 
Table 1: Stipulated repayment functions

\begin{tabular}{lccc}
\hline Type of debt & \multicolumn{3}{c}{ Stipulated repayment } \\
\hline Noncontingent debt & $R(z)$ & $=$ & 1 \\
Linear indexing & $R^{\alpha}(z)$ & $=$ & $1+\alpha\left(y_{2}(z)-\mathbb{E}_{1}\left[y_{2}(z)\right]\right)$ \\
Threshold debt & $R^{\tau}(z)$ & $=$ & $\mathbb{1}\left(y_{2}(z)>\tau\right)$ \\
Optimal design & $R^{\star}(z ; \theta)$ & & chosen state by state \\
\hline
\end{tabular}

Noncontingent debt promises a constant repayment regardless of the state, while the repayment of linearly-indexed debt depends on the difference between realized output and its mean, with a slope parameter of $\alpha \geq 0$. Threshold debt pays only if the state is above a minimum level. Finally, we compute the debt structure that maximizes the utility of the government by promising non-negative repayments $R^{\star}$ state-by-state in a flexible manner. Our notation anticipates that the optimal design depends on the lenders' preferences as summarized by the robustness parameter $\theta$ introduced below. Note that we only allow for indexing to the endowment state and not to the preference-for-default state.

Government The government is benevolent and makes its decisions on a sequential basis. The government acting in period $j \in\{1,2\}$ maximizes $\mathbb{E}\left[\sum_{t=j}^{2} \beta_{b}^{t-j} u\left(c_{t}\right)\right]$, where $\mathbb{E}$ denotes the expectation operator, $\beta_{b} \in(0,1]$ is the government's discount factor, $c_{t}$ represents period- $t$ consumption in the economy, and the utility function $u$ is increasing and concave. The government can borrow to finance consumption in period 1, taking as given the stipulated repayment function $R$. The government may choose to default in period 2. If the government defaults, it does not pay the debt but loses $h(z ; \Delta)$ of the endowment $y_{2}$ and suffers the utility cost $\xi$. We consider a standard quadratic specification for the output-cost function, meant to make the cost of default increasing and convex in the level of output

$$
h(z ; \Delta)=\phi y_{2}(z) \Delta+(1-\phi) y_{2}(z)^{2} \Delta
$$

The government understands the pricing function $q(b)$ that foreign lenders offer for an is- 
suance level $b$. For ease of notation, we omit the dependence of $q$ on $R$ and $\theta$. The government's problem is to choose debt and consumption to solve

$$
\begin{aligned}
& V(\theta, R)=\max _{b} u\left(c_{1}^{b}\right)+\beta_{b} \mathbb{E}\left[u\left(c_{2}^{b}\right)-\xi d(b, z, \xi)\right] \\
& \text { subject to } c_{1}^{b}=y_{1}+q(b) b \\
& c_{2}^{b}=y_{2}(z)-h(z ; \Delta) d(b, z, \xi)-(1-d(b, z, \xi)) R(z) b
\end{aligned}
$$

where $d(b, z, \xi)$ takes the value of 1 if the goverment defaults in state $(b, z, \xi)$ and 0 otherwise. $V(\theta, R)$ denotes the equilibrium value attained by the government when it faces lenders with robustness $\theta$ and issues debt with stipulated repayment $R$. It is common knowledge that the government defaults in the second period if and only if

$$
u\left(y_{2}(z)-h(z ; \Delta)\right)-\xi>u\left(y_{2}(z)-R(z) b\right)
$$

Lenders We focus on the interaction between the design of the debt instrument and the lenders' degree of robustness. Following Hansen and Sargent (2001) and Pouzo and Presno (2016), we assume that foreign lenders feature multiplier preferences to capture concerns about potential model misspecification. Multiplier preferences lead our lenders to price assets by distorting their approximating or benchmark model. They seek rules that perform well under a variety of possible models that are statistically close to their benchmark. A common metaphor is that lenders choose their actions to maximize utility while a fictitious 'evil agent' chooses a probability distribution to minimize that same utility. The result is an action that performs well even in unfavorable circumstances. The overall utility includes a gain from the entropy of the distribution used with respect to the benchmark model (resulting in an entropy cost incurred by the evil agent). The key parameter is the reciprocal of the marginal cost of relative entropy, $\theta .^{7}$

\footnotetext{
${ }^{7}$ Pouzo and Presno (2016) provide a thorough discussion of robustness in the context of sovereign debt models.
} 
Standard arguments from the robustness literature allow us to write the lenders' problem as

$$
\max u\left(c_{1}^{L}\right)-\frac{\beta}{\theta} \log \left(\mathbb{E}\left[\exp \left(-\theta v_{2}^{L}\right)\right]\right)
$$

$$
\begin{aligned}
\text { subject to } v_{2}^{L} & =u\left(c_{2}^{L}\right) \\
c_{2}^{L} & =w_{2}+(1-d(b, z, \xi)) R(z) b \\
c_{1}^{L} & =w_{1}-q_{1} b
\end{aligned}
$$

where $\left(w_{1}, w_{2}\right)$ are the lenders' endowments in periods 1 and 2 , respectively. ${ }^{8}$

The lenders' first-order conditions yield a pricing equation for the debt

$$
u^{\prime}\left(c_{1}^{L}\right) q(b ; R)=\beta \mathbb{E}\left[\frac{\exp \left(-\theta u\left(c_{2}^{L}\right)\right)}{\mathbb{E}\left[\exp \left(-\theta u\left(c_{2}^{L}\right)\right)\right]} u^{\prime}\left(c_{2}^{L}\right)(1-d(b, z, \xi)) R(z)\right]
$$

where $M=\beta \frac{\exp \left(-\theta u\left(c_{2}^{L}\right)\right)}{\mathbb{E}\left[\exp \left(-\theta u\left(c_{2}^{L}\right)\right)\right]}$ augments the stochastic discount factor. The parameter $\theta$ controls the degree of ambiguity aversion. This Euler equation makes it clear that the model converges back to expected utility with rational expectations as $\theta \rightarrow 0$. In our baseline, lenders have per-period payoff linear in consumption, while also being uncertainty averse or ambiguity averse. ${ }^{9}$

Ambiguity premia The robust-lenders model allows to link bond prices and spreads to different features of equilibrium expectations about debt repayments. For risk-neutral (but still robust) lenders, we have

$$
\begin{aligned}
q(b, R) & =\beta \mathbb{E}\left[\frac{\exp \left(-\theta c_{2}^{L}\right)}{\mathbb{E}\left[\exp \left(-\theta c_{2}^{L}\right)\right]}(1-d(b, z, \xi)) R(z)\right] \\
& =\underbrace{\beta \mathbb{E}[(1-d) R]}_{=q_{R E}}+\underbrace{\mathbb{E}[1-d] \operatorname{cov}(M, R)}_{=q_{\theta}^{\text {cont }}}+\underbrace{\mathbb{E}[R] \operatorname{cov}(1-d, M)}_{=q_{\theta}^{\text {def }}}
\end{aligned}
$$

Equation (1) breaks up the debt price into a rational-expectations component $q_{R E}$ and two

\footnotetext{
${ }^{8}$ In the case of risk-averse lenders, the relative size of their endowments can also be important in shaping their risk-appetite. Moreover, in general, lenders can be affected by developments in the economy through a correlation between these quantities and the endowment shocks.

${ }^{9}$ We leave the lenders' utility function general, even though we focus on the risk-neutral case. In general, it can be jointly calibrated along with the robustness parameter $\theta$ to match asset-pricing evidence. Another alternative is to calibrate $\theta$ to a reasonable model error-detection probability.
} 
components that depend on the degree of robustness. The first of them, $q_{\theta}^{\text {cont }}$, reflects ambiguity in the contingency of debt: given the repayment probability, it is proportional to the covariance between the stochastic discount factor and the contingency in stipulated repayments. The second one, $q_{\theta}^{d e f}$, reflects ambiguity in the default strategy: controlling for the average level of stipulated repayments, it is proportional to the covariance between the stochastic discount factor and the repayment strategy. Because the lenders' marginal utility is decreasing in the debt repayment, both covariances will typically be negative. Both ambiguity terms contribute to lower bond prices and larger spreads.

We compute and decompose spreads as follows. Let $r=\frac{\mathbb{E}[R]}{q}$ be the implicit interest rate and $r-r^{\star}$ be the spread, where $r^{\star}=1 / \beta-1$ is the international risk-free rate. We define the rational-expectations spread as $s p r_{\mathrm{RE}}=\frac{\mathbb{E}[R]}{q_{\mathrm{RE}}}-r^{\star}$, the premium from the ambiguity of contingent repayment as $\operatorname{spr}_{\theta}^{\text {cont }}=\frac{\mathbb{E}[R]}{q_{\mathrm{RE}}+q_{\theta}^{\text {cont }}}-\frac{\mathbb{E}[R]}{q_{\mathrm{RE}}}$, and the premium from the ambiguity of default as $s p r_{\theta}^{d e f}=$ $\frac{\mathbb{E}[R]}{q_{\mathrm{RE}}+q_{\theta}^{\text {cont }}+q_{\theta}^{\text {def }}}-\frac{\mathbb{E}[R]}{q_{\mathrm{RE}}+q_{\theta}^{\text {cont }}}$.

The robust-lenders model allows us to characterize the probability distortions that underpin debt prices in an equilibrium. We define a distorted expectation of a random variable $X$ as the objective expectation of the product of $X$ with a likelihood ratio

$$
\tilde{\mathbb{E}}[X]=\mathbb{E}\left[\frac{\exp \left(-\theta u\left(c_{2}^{L}\right)\right)}{\mathbb{E}\left[\exp \left(-\theta u\left(c_{2}^{L}\right)\right]\right.} X\right]
$$

As compared to the expectation taken with the objective probability measure, the distorted expectation magnifies the likelihood of states for which the lenders' utility is low. Different designs for government debt (different $R$ functions) lead to different equilibrium outcomes for lenders, which in turn support different worst-case models and different probability distortions.

\subsection{Probability Distortions}

To investigate the effect of robustness on state-contingent debt prices, we solve the stylized model for different repayment functions $R$ and different levels of the robustness parameter $\theta$. We lever- 
age Equation (2) to recover the probability distortions used by lenders to evaluate debt payoffs in each equilibrium.

Table 2 summarizes our parametrization. We keep close to the Argentinian GDP-linked bonds described in Costa, Chamon, and Ricci (2008). One important aspect of their description is that

Table 2: Parametrization of stylized model

\begin{tabular}{lcc}
\hline Parameter & Target & Value \\
\hline$\beta_{b}$ & Borrower's discount rate & $6 \%$ ann. \\
$\beta$ & Risk-free rate & $3 \%$ ann. \\
$\gamma$ & Borrower's risk aversion & 2 \\
$\Delta$ & Output cost of default & $20 \%$ \\
$\phi$ & Weight of linear cost & 0 \\
$g$ & Expected growth rate & $8 \%$ ann. \\
$\tau$ & Threshold for repayment & 1 \\
$\sigma_{z}$ & Std. deviation of log output & 0.15 \\
\hline
\end{tabular}

the presence of other, noncontingent securities creates default risk in the GDP-warrants because of the incentive to default on all debts at once. We make use of the government's preference shock $\xi$ to account for this fact in the stylized model. ${ }^{10}$

One period is five years. We set the first period endowment $y_{1}$ to make $\mathbb{E}\left[y_{2}(z)\right]=1=$ $y_{1}(1+g)^{5}$, so that $g$ is the expected growth rate. ${ }^{11}$ The output cost of default $\Delta$ as well as expected growth $g$ are set to a high value to simultaneously generate high levels of debt and a low default probability, which is complicated in this stylized model by the use of one-period bonds (this difficulty is absent in our quantitative version with long-term debt). Other parameters are set to standard values in the literature.

The shock processes are set as follows. Output in the second period $y_{2}(z)=\exp (z)$ where $z$ follows a Normal distribution with mean 0 and standard deviation $\sigma_{z}$. The utility cost of default $\xi$ is constructed by the following mixture: with probability $3 \%, \xi=\bar{\xi}$, a (negative) value so large that the government defaults regardless of fundamentals. This value is meant to capture the default

\footnotetext{
${ }^{10}$ In the quantitative version, we peg our parameters to calibrations based entirely on noncontingent debt and evaluate a move towards state-contingent debt.

${ }^{11}$ While foreign lenders agree about the second equality, their worst-case model will in general yield a distorted expectation $\tilde{\mathbb{E}}\left[y_{2}(z)\right]<1$.
} 
probability that Costa, Chamon, and Ricci (2008) attribute to the default risk of other securities which we do not model. With the remaining probability, $\xi$ is distributed Uniform between 0 and $0.01 .^{12}$

We parametrize our threshold bond structure as follows. We set the repayment threshold $\tau$ at the mean of output in the second period. This is meant to replicate the fact that the Argentinian GDP-linked bond was designed to pay if output growth was above average. At the time of issuance, the Consensus Forecast for Argentina's GDP growth was about 3\% over the medium-term, which coincides with the bond's main condition for repayment.

Simple state-contingent instruments We begin by analyzing equilibrium outcomes associated with some simple bond structures: noncontingent debt, linearly-indexed debt, and threshold debt.

Figure 1 shows the probability distortions when the government issues noncontingent bonds. For ease of exposition, we fix the amount of debt issued at the optimal level when $\theta=0$ (the rational-expectations case), so that the default probability does not vary with the degree of robustness. ${ }^{13}$ The top panel shows the default probability at each state as a dotted line and the distorted density (used by lenders to evaluate payoffs) in solid lines. The bottom panel shows the stipulated payment $R$ as a dashed line and the likelihood ratios $\frac{\exp \left(-\theta c_{2}^{L}\right)}{\mathbb{E}\left[\exp \left(-\theta c_{2}^{L}\right)\right]}$ in solid lines. The distorted density used by lenders equals the likelihood ratio times the objective density.

In the case of noncontingent debt, the expected repayment is almost a step function of the state $z$. When the endowment is low enough, the default probability jumps to 1 . The lenders' stochastic discount factor is therefore also almost a step function of the state, as marginal utility of lenders is constant (and high) to the left of the jump and constant (and low) to the right of it. As the robustness parameter $\theta$ increases, the metaphorical evil agent has more scope to distort

\footnotetext{
${ }^{12}$ This serves a mostly numerical purpose of smoothing some expectations and does not affect our qualitative conclusions.

${ }^{13}$ When the government can optimize issuances as a function of $\theta$, as we will see later, it issues less debt as lenders become more robust and charge higher spreads. This makes the default probability at any given $z$ a decreasing function of $\theta$.
} 


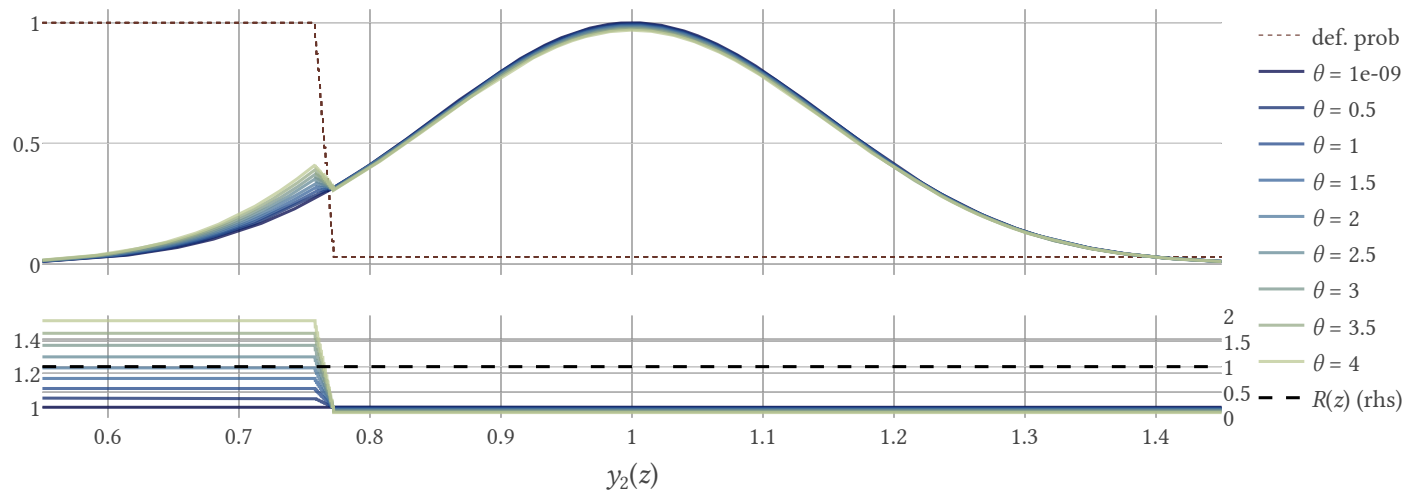

Figure 1: Distorted probabilities when the government issues noncontingent debt.

probabilities, and does so by assessing the default set as more likely. For higher values of $\theta$, therefore, the expected return of the debt (under the distorted density) is lower and lenders require higher spreads in order to hold it.

Indexing debt repayments linearly to second-period output has two consequences, illustrated in Figure 2, which is computed for an indexing coefficient $\alpha=1$. On the one hand, stipulating

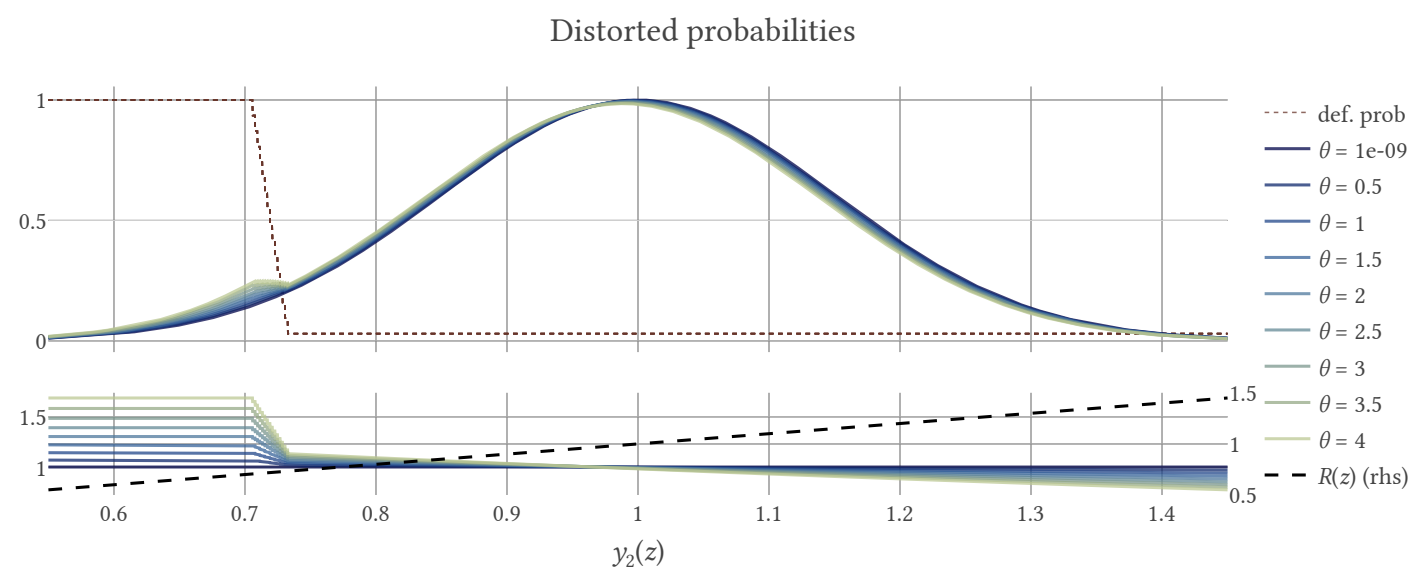

Figure 2: Distorted probabilities when the government issues linearly-indexed debt.

lower repayments when output is lower successfully shrinks the ex-post default set. However, it also affects the robust lenders' probability distortions: states with higher repayments are distorted downward, resulting in an overall shift to the left of the (distorted) distribution. When debt is indexed linearly, lenders act almost as if the output process had a lower mean. As before, 
the amount of distortion (but not its shape) increases with the robustness parameter $\theta$. Higher values of $\alpha$ shrink the default set but enable stronger probability distortions. How this tradeoff is resolved depends on the degree the robustness.

Finally, Figure 3 considers the case of the threshold bond which promises to repay 1 unit of the good if the state is above its mean (under the approximating model which is shared by government and lenders) and 0 otherwise. In this case, the probability distortions are much more

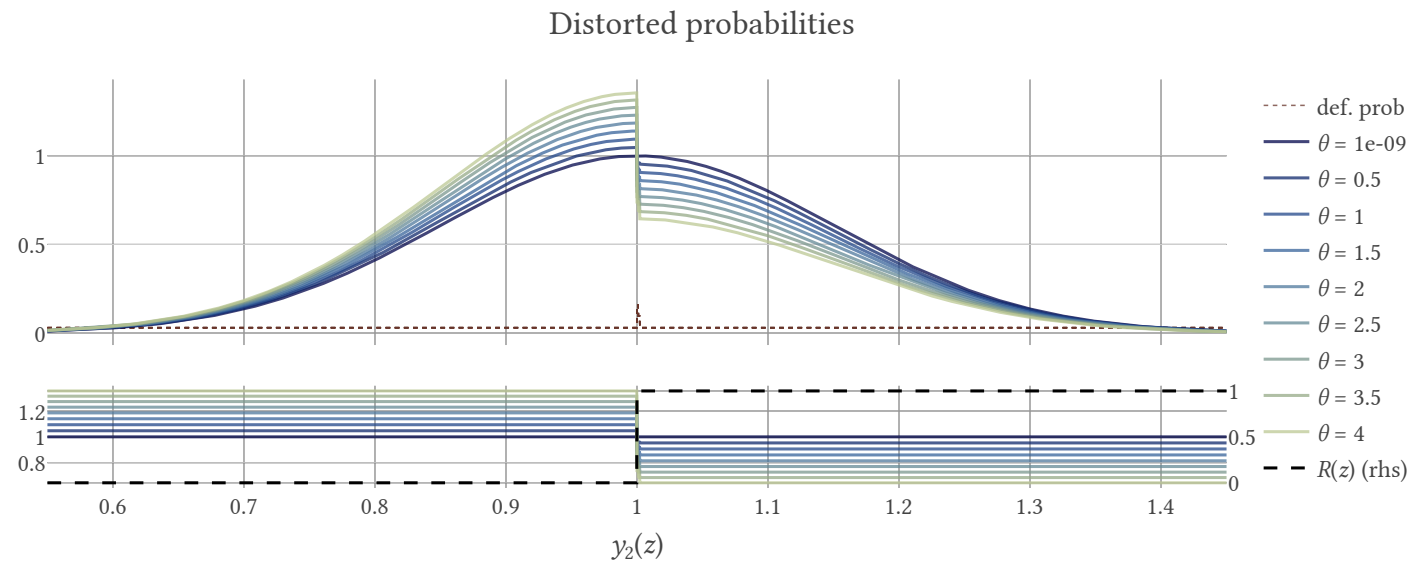

Figure 3: Distorted probabilities when the government issues the threshold bond.

striking. The jump in stipulated repayments creates a jump in the probability distortions. As we will see later, the large distortions evident in Figure 3 manifest as high spreads that negate the gains from contingency in repayment.

Optimal debt design We turn our attention to the problem of how to design state-contingent debt instruments and how the optimal design changes with the degree of robustness. When facing lenders with robustness parameter $\theta$, let $R^{\star}(z ; \theta)$ maximize the equilibrium value attained by the government $V(\theta, R)$, subject to a non-negativity constraint.

Figure 4 is based on the case in which the repayment function $R(z)$ is optimized given that lenders have rational expectations $(\theta \rightarrow 0)$. The optimal repayment function in this case has a region where it promises zero repayments (the constraint $R \geq 0$ binds), followed by a region where repayments are increasing in the level of output. This type of debt makes the default 


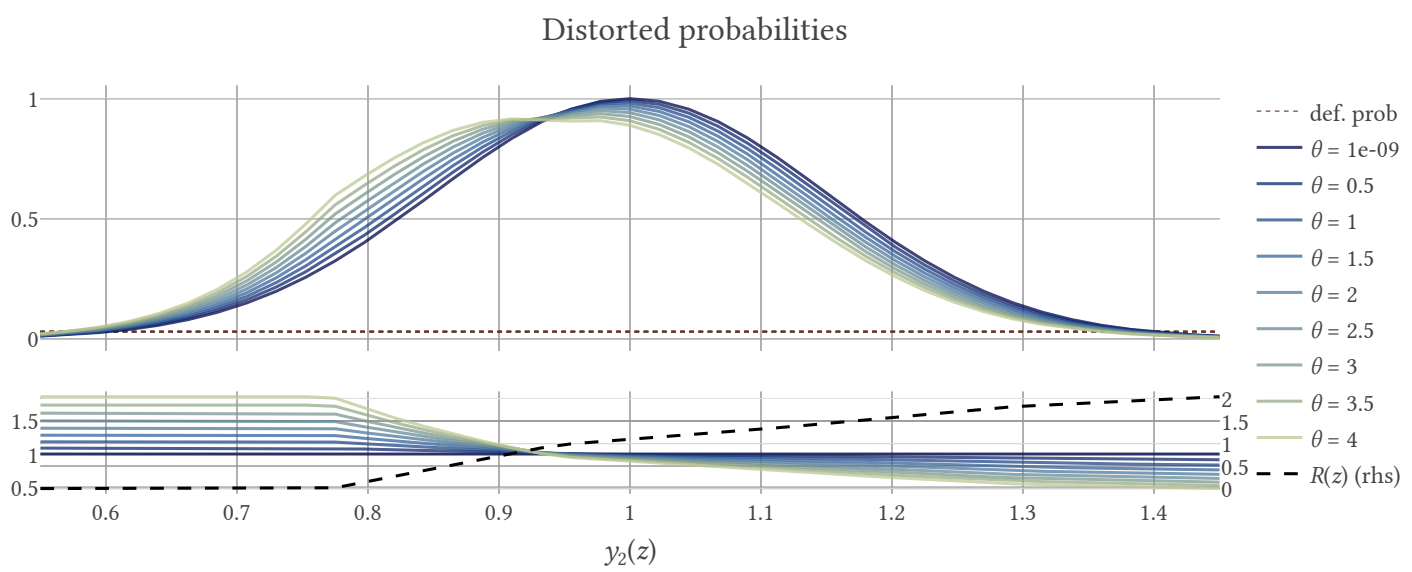

Figure 4: Distorted probabilities when the government issues debt with the optimal indexation for RE lenders.

set empty (the government only defaults with $\xi=\bar{\xi}$ ) and takes advantage of contingency in repayments. Because of this, the debt designed for rational-expectations lenders is subject to large probability distortions (albeit less than the threshold debt) when evaluated by robust lenders.

Figure 5 illustrates the opposite exercise: debt designed for lenders with the highest level of robustness we consider (a value of $\theta=4$ ). In this case, the tradeoff between contingency and

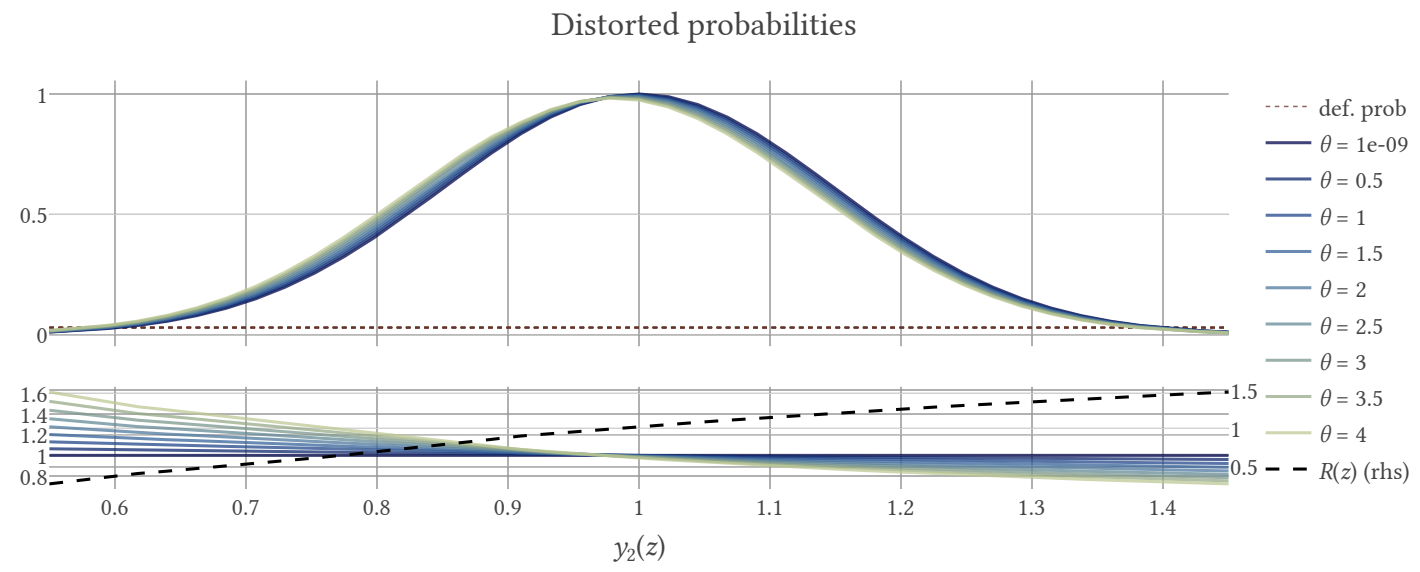

Figure 5: Distorted probabilities when the government issues debt with the optimal indexation for robust lenders.

enabling probability distortions is resolved by a debt design which varies much less with the state. As a result, the probability distortions are much milder, at all levels of $\theta$.

Finally, Figure 6 shows the optimal design of state-contingent debt $R^{\star}(z ; \theta)=\arg \max _{R} V(\theta, R)$ 
for each value of the robustness parameter $\theta$, as well as the expected repayment (factoring in the default probability) of noncontingent debt. It is clear that, as $\theta$ increases, the optimal debt structure features less contingency, lower slopes, and an avoidance of regions with zero or low stipulated repayments. Figure 6 sharply illustrates the tradeoffs in the debt-design problem when

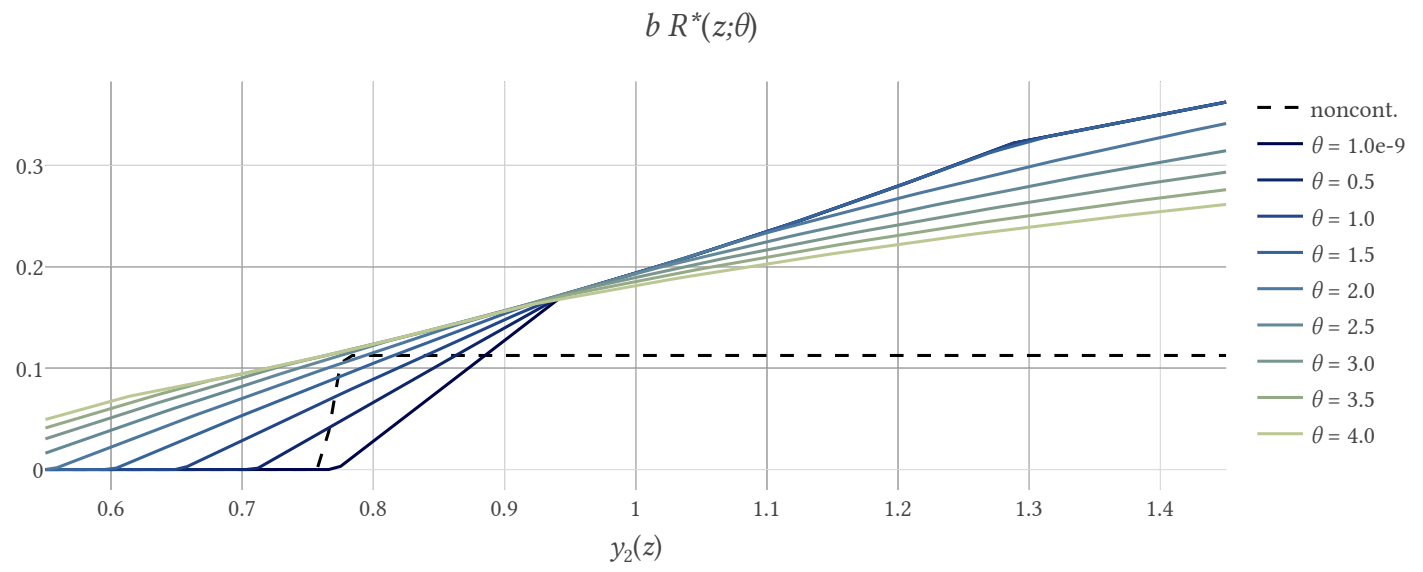

Figure 6: Optimal design of state-contingent debt for each type of lender.

facing robust lenders. On the one hand, the government would like to minimize the contingency in stipulated repayments in order to prevent probability distortions. But the government also needs to minimize another source of contingency given by default risk ex-post. In low states, the government promises as much as it can credibly commit to repay.

\subsection{Spreads}

We now turn to how the probability distortions and concerns for model misspecification affect bond prices, issuances, and the government's welfare in equilibrium. The top panel of Figure 7 shows our decomposition of equilibrium spreads as a function of the robustness parameter $\theta$. The bottom panel shows the issuance value $q(b) b$ as well as the welfare of the government. We measure welfare as the equivalent increase in consumption with respect to an equilibrium with the same $\theta$ but when the government issues noncontingent debt. ${ }^{14}$

\footnotetext{
${ }^{14}$ Somewhat abusing notation, if

$$
V(\theta, R, x)=u\left(c_{1}^{b}(1+x)\right)+\beta \mathbb{E}\left[u\left(c_{2}^{b}(1+x)\right)-\xi d(b, z, \xi)\right]
$$
}




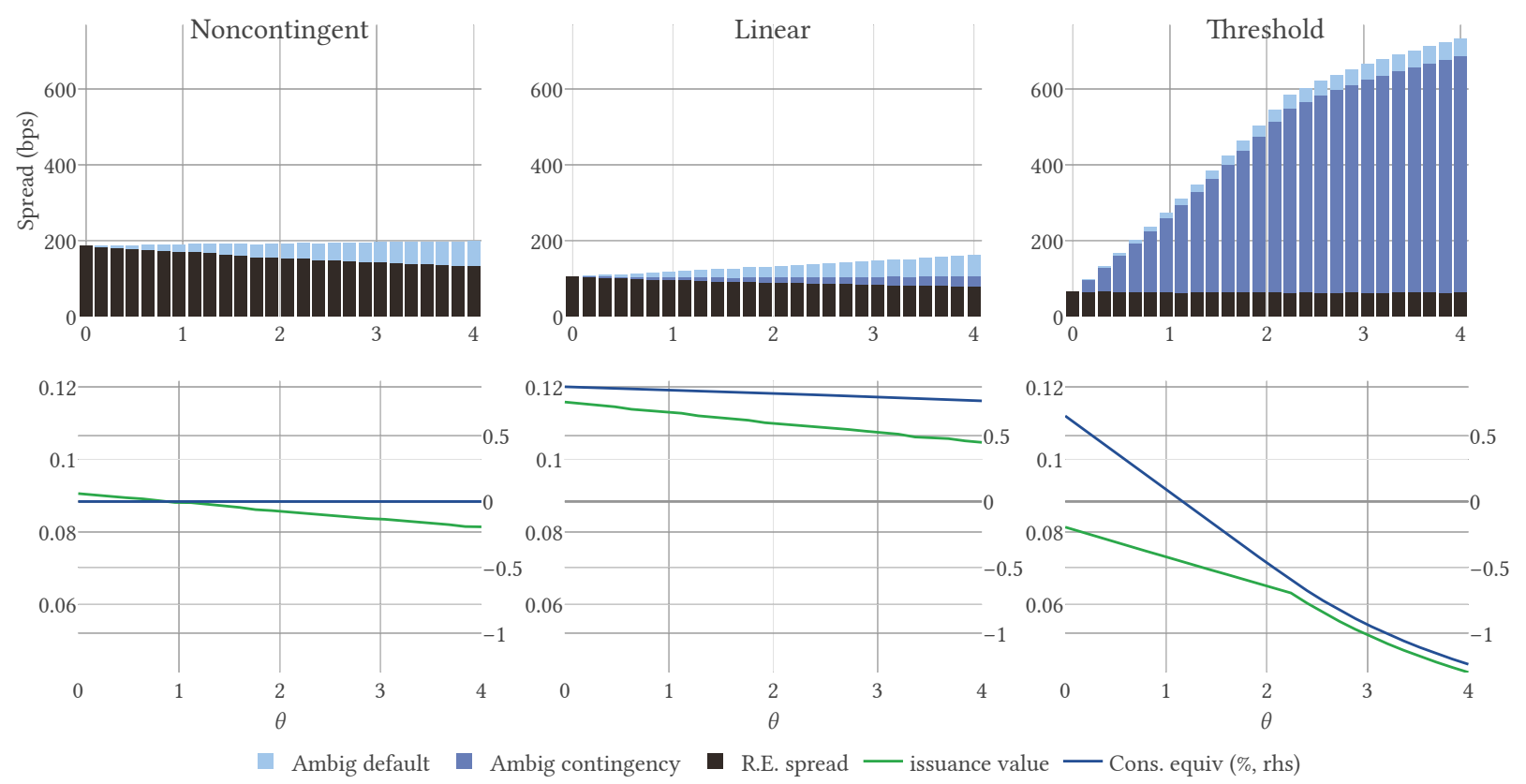

Figure 7: Spreads when the government issues the simple instruments

When the government issues noncontingent debt, more robust lenders charge a higher spread for the ambiguity of default. The government responds by issuing lower amounts of debt. In our parametrization, the decrease in the default probability (the amount of risk) roughly compensates the increase in the spreads because of ambiguity (the price of risk).

Linearly-indexed debt successfully decreases the equilibrium default probability, as evidenced by lower spreads under rational-expectations. This leads to welfare gains equivalent to about $0.9 \%$ of consumption from the noncontingent debt benchmark. As robustness increases, spreads from ambiguity of contingency and from ambiguity of default open up, eroding the government's ability to issue debt and therefore welfare gains. At $\theta=4$, however, the government still values the option to move from noncontingent to linearly-indexed debt at about $0.75 \%$ of consumption.

The picture is quite different for threshold debt. Although this type of debt eliminates default risk related to $y_{2}(z)$, there are spreads from the risk that default is triggered by the event $\xi=\bar{\xi}$. is the value attained by the government, augmenting the equilibrium level of consumption by the factor $x$, then in each equilibrium with bonds $R$ and robustness $\theta$ we measure welfare by finding $x$ to make $V(\theta, R, 0)=V(\theta, 1, x)$. 
The large probability distortions discussed above support large spreads from the ambiguity of contingency. These high spreads quickly turn the welfare gains from state-contingent debt into welfare losses.

Figure 8 repeats the exercise for our optimally-designed instruments. In the case of debt
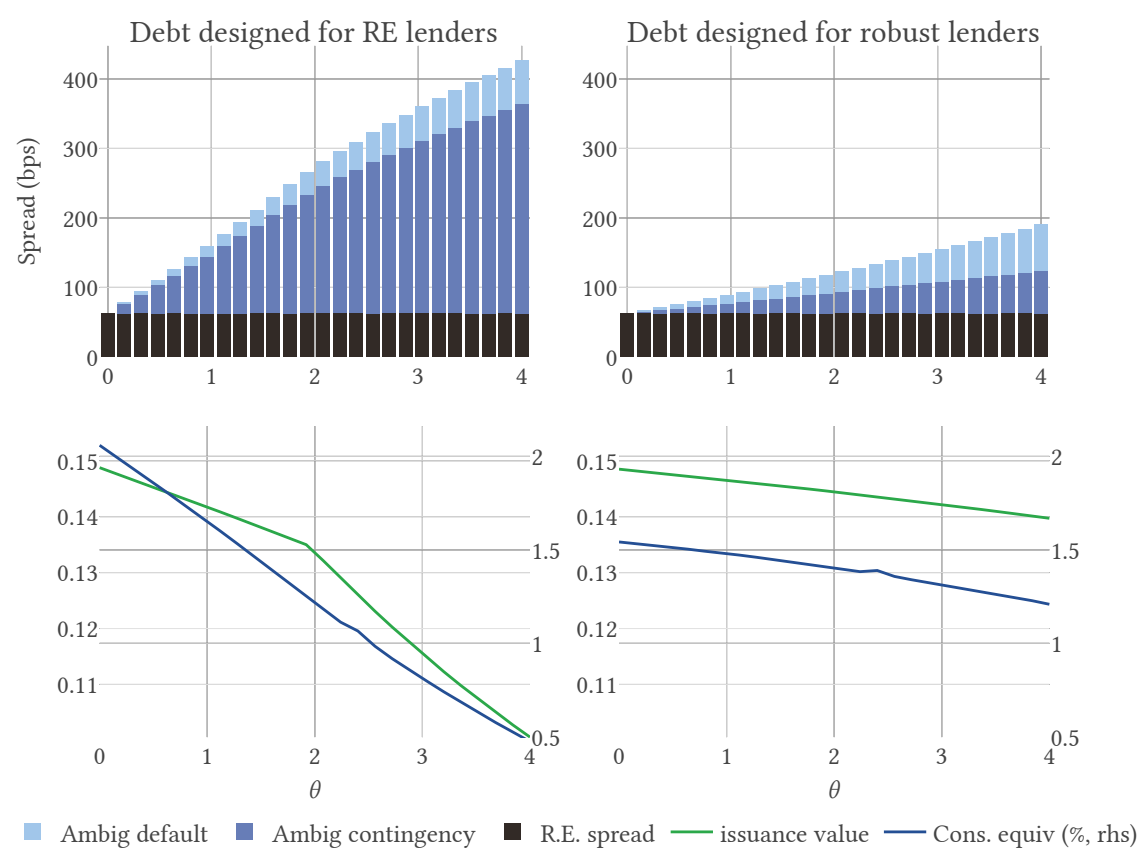

Figure 8: Spreads when the government issues the optimally indexed instruments

designed for rational-expectations lenders, large spreads from the ambiguity of contingency arise as lenders become more robust. Because the contingency introduced by this type of debt is less severe than the threshold debt studied above, the gains from issuing this type of state-contingent debt evaporate more slowly and remain positive at all values of $\theta$. Finally, debt designed for robust lenders implies lower gains when priced by rational-expectations lenders, but these gains remain high as robustness increases. The effort to create little ex-ante and ex-post contingency in this type of debt keeps the ambiguity spreads at bay. 


\section{The quantitative model}

In this section we present the infinite-horizon version of the two-period model studied in Section 3. We consider a general formulation in which the government can issue contingent defaultable debt and discuss how this nests the benchmark case with noncontingent debt as a special case.

Endowment There is a single tradable good. The economy receives a stochastic endowment stream of this good $x_{t}$, which is dictated by persistent and transitory shocks. The transitory component of the endowment process $m_{t}$ is an iid shock. ${ }^{15}$ The persistent component of the endowment process $y_{t}$ follows a Markov process and takes values in the set $\mathcal{Y}=\left\{y_{1}, \ldots, y_{J}\right\}$. While the true density of this process is unknown, the government trusts that the evolution of $y_{t}$ is governed by the approximating model with probabilities $\mathbb{P}\left(y_{t+1}=y_{j} \mid y_{t}=y_{i}\right)>0$ for all $i, j=1, \ldots, J$.

Government The government's objective is to maximize the present expected discounted value of future utility flows of the representative household in the economy, namely

$$
\mathbb{E}_{t}\left[\sum_{s=0}^{\infty} \beta^{s} u\left(c_{t+s}\right)\right],
$$

where $\mathbb{E}$ denotes the expectation operator, $\beta$ denotes the subjective discount factor, and $c_{t}$ represents household's consumption. The utility function is strictly increasing and concave.

As in Hatchondo and Martinez (2009) and Arellano and Ramanarayanan (2012), we assume that a bond issued in period $t$ promises an infinite stream of coupons, which decreases at a constant rate $\delta$. However, we expand this framework by making coupon payments vary with the realization of $y_{t}$. We allow coupon payments to depend linearly on $y_{t}$ as well as threshold-based rules. In particular, a bond issued in period $t$ promises to pay $\max \left\{0,\left(1+\alpha\left(y_{t}-1\right)\right) \mathbb{1}\left(y_{t}>\tau\right)\right\}$ units of the good in period $t+1$ and $\max \left\{0,(1-\delta)^{s-1}\left(1+\alpha\left(y_{s}-1\right)\right) \mathbb{1}\left(y_{s}>\tau\right)\right\}$ units in period $t+s$,

\footnotetext{
${ }^{15}$ This random variable is introduced for computational issues when solving the model as discussed in Chatterjee and Eyigungor (2012).
} 
with $s \geq 2$. The parameters $\alpha, \tau$ determine the degree of linear indexation and coupon repayment income threshold, respectively. This bond structure allows us to keep the same recursive formulation of the model presented in the literature. Note that when $\alpha=0$ and $\tau=-\infty$ we recover the benchmark model with noncontingent bonds.

At the beginning of each period in which it is not in default, the government makes two decisions. First, it decides whether to default. Second, if it chose to repay, it chooses the number of bonds that it purchases or issues in the current period. We follow the literature and assume that, because of acceleration and cross-default clauses, the government cannot discriminate among its creditors or otherwise engineer a partial default. We also assume that the fraction of the loan lenders can recover after a default (the recovery rate) is zero.

There are two costs of defaulting. First, a defaulting sovereign is excluded from capital markets. In each period after the default period, the country regains access to capital markets with probability $\psi \in[0,1] .{ }^{16}$ Second, if a country has defaulted on its debt, it faces an income loss of $\phi(y)$ in every period in which it is excluded from capital markets.

Lenders Our departure from the standard setup is to allow for lenders who fear model misspecification. We follow Pouzo and Presno (2016) by considering that the lenders' have per period payoff linear in consumption, while also being ambiguity averse with respect to the probability distribution of $y_{t} \cdot{ }^{17}$ Unlike the government, lenders distrust the approximating model. They look for decision rules that are robust to possible errors in the estimated process, by surrounding the approximating density with other densities offering a similar fit to the data and choosing a sequence of distorted conditional probabilities that minimize their expected utility. In particular, we adopt the Hansen and Sargent (2001) multiplier preferences model, which captures ambiguity aversion by a single parameter, to derive a theoretically-founded measure of lenders' ambiguity

\footnotetext{
${ }^{16}$ Hatchondo, Martinez, and Sapriza (2007) solve a baseline model of sovereign default with and without the exclusion cost and show that eliminating this cost affects significantly only the debt level generated by the model.

${ }^{17}$ As in the stylized model, this assumption makes the size of the lenders' endowment (relative to the small open economy) irrelevant.
} 
aversion. In this framework, model uncertainty generates a risk premium without the need for correlation between foreign investors' wealth and default. Foreign lenders charge a premium on defaultable debt in order to guard themselves against possible specification errors in the estimated income process.

\subsection{Recursive formulation}

Let $b$ denote the number of outstanding coupon claims at the beginning of the current period, and $b^{\prime}$ denote the number of outstanding coupon claims at the beginning of the next period. A negative value of $b$ implies that the government was a net issuer of bonds in the past. Let $d$ denote the current-period default decision. We assume that $d$ is equal to 1 if the government defaulted in the current period and is equal to 0 if it did not. Let $V$ denote the government's value function at the beginning of a period, before the default decision is made. Let $V_{0}$ denote the value function of a sovereign not in default. Let $V_{1}$ denote the value function of a sovereign in default. Let $F$ denote the conditional cumulative distribution function of the next-period endowment $y^{\prime}$. For any bond price function $q$, the function $V$ satisfies the following functional equation:

$$
V(b, y, m)=\max _{d \epsilon\{0,1\}}\left\{d V_{1}(y, m)+(1-d) V_{0}(b, y, m)\right\}
$$

where

$$
\begin{aligned}
& V_{1}(y, m)=u(y+m-\phi(y))+\beta \int\left[\psi V\left(0, y^{\prime}, m^{\prime}\right)+(1-\psi) V_{1}\left(y^{\prime}, m^{\prime}\right)\right] F\left(d y^{\prime} \mid y\right), \\
& V_{0}(b, y, m)=\max _{b^{\prime} \leq 0}\left\{u(c)+\beta \int V\left(b^{\prime}, y^{\prime}, m^{\prime}\right) F\left(d y^{\prime} \mid y\right)\right\} \\
& \text { subject to } c=y+m+b \max \{0,(1+\alpha(y-1)) \mathbb{1}(y>\tau)\}-q\left(b^{\prime}, y\right)\left[b^{\prime}-(1-\delta) b\right] .
\end{aligned}
$$

Let $W$ denote the lenders' value function at the beginning of a period, before the default decision is made. The problem of a robust lender that fears model misspecification can be expressed 
in recursive form as

$$
W(b, y)=\max c^{L}-\frac{\beta^{L}}{\theta} \log \left(\mathbb{E}\left[\exp \left(-\theta W\left(b^{\prime}, y^{\prime}\right)\right)\right]\right)
$$

subject to

$$
c^{L}=\bar{z}+(1-d(b, y, m))\left[q\left(b^{\prime}, y\right)\left(b^{\prime}-(1-\delta) b\right)-b \max \{0,(1+\alpha(y-1)) \mathbb{1}(y>\tau)\}\right],
$$

where the parameter $\theta$ encapsulates the degree of lenders' ambiguity aversion.

In this framework, bond prices are such that uncertainty-averse lenders make zero profits in expectation given their subjective beliefs. The bond price is given by the following functional equation:

$$
\begin{aligned}
q\left(b^{\prime}, y\right)= & \int M\left(b^{\prime}, y^{\prime}, y\right)\left[\left(1-h\left(b^{\prime}, y^{\prime}, m^{\prime}\right)\right) \max \left\{0,(1+\alpha(y-1)) \mathbb{1}\left(y>\tau_{y}\right)\right\}\right] F\left(d y^{\prime} \mid y\right) \\
& +(1-\delta) \int M\left(b^{\prime}, y^{\prime}, y\right)\left[1-h\left(b^{\prime}, y^{\prime}, m^{\prime}\right)\right] q\left(g\left(b^{\prime}, y^{\prime}, m^{\prime}\right), y^{\prime}\right) F\left(d y^{\prime} \mid y\right),
\end{aligned}
$$

where $h$ and $g$ denote the future default and borrowing rules that lenders expect the government to follow. The default rule $h$ is equal to 1 if the government defaults, and is equal to 0 otherwise. The function $g$ determines the number of coupons that will mature next period. The first term in the right-hand side of equation (7) equals the expected value of the next-period coupon payment promised in a bond. The second term in the right-hand side of equation (7) equals the expected value of all other future coupon payments, which is summarized by the expected price at which the bond could be sold next period. ${ }^{18}$ The lenders' stochastic discount factor, $M\left(b^{\prime}, y^{\prime}, y\right)$, is made of two parts. First, an ordinary discount factor $\beta^{L}$ that applies in cases without model uncertainty. Second, an ambiguity-aversion factor, which is given by the conditional likelihood ratio of the endogenous worst-case distorted model relative to the approximating model

$$
M\left(b^{\prime}, y^{\prime}, y\right)=\beta^{L} \frac{\exp \left(-\frac{W\left(b^{\prime}, y^{\prime}\right)}{\theta}\right)}{\mathbb{E}\left[\exp \left(-\frac{W\left(b^{\prime}, y^{\prime}\right)}{\theta}\right)\right]}
$$

\footnotetext{
${ }^{18}$ In a similar environment with risk-neutral (but non-robust) lenders, Chatterjee and Eyigungor (2012) demonstrate that an equilibrium bond price function exist and is decreasing with respect to the debt level.
} 
Equations (3)-(7) illustrate that the government finds its optimal current default and borrowing decisions taking as given its future default and borrowing decision rules $h$ and $g$. In equilibrium, the optimal default and borrowing rules that solve problems (3) and (5) must be equal to $h$ and $g$ for all possible values of the state variables.

Definition 1. A Markov Perfect Equilibrium is characterized by

1. a set of value functions $W, V, V_{1}$, and $V_{0}$

2. a default rule $h$ and a borrowing rule $g$,

3. a bond price function $q$,

such that:

(a) given $h$ and $g, V, V_{1}, V_{0}$, and $W$ satisfy functional equations (3), (4), (5), and (6) when the government can trade bonds at $q$;

(b) given $h$ and $g$, the bond price function $q$ is given by equation (7); and

(c) the default rule $h$ and borrowing rule $g$ solve the dynamic programming problem defined by equations (3) and (5) when the government can trade bonds at $q$.

\subsection{Calibration}

The utility function is assumed to display a constant coefficient of relative risk aversion denoted by $\gamma$. That is,

$$
u(c)=\frac{c^{1-\gamma}-1}{1-\gamma} .
$$

The persistent component of the endowment $y_{t}$ follows an AR1 process in logs

$$
\log \left(y_{t}\right)=\rho \log \left(y_{t-1}\right)+\varepsilon_{t},
$$


with $|\rho|<1$, and $\varepsilon_{t} \sim \mathcal{N}\left(0, \sigma_{\epsilon}^{2}\right)$. Following Chatterjee and Eyigungor (2012), we assume a quadratic loss function for income during a default episode $\phi(y)=d_{0} y+d_{1} y^{2}$.

Table 3: Parameter values for the baseline parametrizations.

\begin{tabular}{lccc}
\hline & Parameter & $\begin{array}{c}\text { Chatterjee and } \\
\text { Eyigungor (2012) }\end{array}$ & $\begin{array}{c}\text { Pouzo and Presno } \\
(\mathbf{2 0 1 6 )}\end{array}$ \\
\hline Sovereign's risk aversion & $\gamma$ & 2 & 2 \\
Interest rate & $r$ & 0.01 & 0.01 \\
Income autocorrelation coefficient & $\rho$ & 0.9485 & 0.9484 \\
Standard deviation of innovations & $\sigma_{\epsilon}$ & 0.027 & 0.02 \\
Reentry probability & $\psi$ & 0.0385 & 0.0385 \\
Duration of debt & $\delta$ & 0.05 & 0.05 \\
Discount factor & $\beta$ & 0.95402 & 0.9627 \\
Default cost: linear & $d_{0}$ & -0.18819 & -0.255 \\
Default cost: quadratic & $d_{1}$ & 0.24558 & 0.296 \\
Degree of robustness & $\theta$ & 0 & 1.62 \\
Linear coupon indexation & $\alpha$ & 0 & 0 \\
Coupon repayment threshold & $\tau$ & $-\infty$ & $-\infty$ \\
\hline
\end{tabular}

We solve the model for the parametrizations presented by Chatterjee and Eyigungor (2012) and Pouzo and Presno (2016). Table 3 shows the parameter values for each calibration. As in many previous quantitative studies on sovereign default, both papers use Argentina before the 2001 default as a case study. A period in the model refers to a quarter. These calibrations assume noncontingent bonds which in our framework implies setting $\alpha=0$ and $\tau=-\infty$. The representative household in the sovereign economy has a coefficient of relative risk aversion of 2 , which is standard in studies of business cycles. The risk-free interest rate is set to 1 percent. Parameter values that govern the endowment process are chosen so as to mimic the behavior of GDP in Argentina from the first quarter of 1993 to the last quarter of 2001. The parametrization of the income process is similar to the one used in other studies that consider a longer sample period (see, for instance, Aguiar and Gopinath, 2006). Both calibrations assume a probability of regaining access to capital markets that implies an average period of 6.5 years of financial exclusion. With $\delta=0.05$, noncontingent bonds have an average maturity of 5 years under both parametrizations of the benchmark model. 
Both papers calibrate the discount factor and the income cost of defaulting (two parameter values) to target three moments: the mean spread (both target 8.15 percent), the standard deviation of the spread (Chatterjee and Eyigungor, 2012 target 4.43 percent while Pouzo and Presno, 2016 target 4.58 percent), and the mean debt to (annual) GDP ratio (Chatterjee and Eyigungor, 2012 target 70 percent while Pouzo and Presno, 2016 target 46 percent). Finally, Chatterjee and Eyigungor (2012) does not study amiguity averse lenders and, thus, the model is equivalent to setting $\theta=0$ in our framework. However, Pouzo and Presno (2016) show that augmenting the standard model with robust lenders allows the model to fit the spread and default frequency levels simultaneously. Thus, Pouzo and Presno (2016) calibrates the degree of robustness to target a default frequency of three defaults per 100 years. ${ }^{19}$ The targets for the spread distribution are taken from the spread behavior in Argentina before its 2001 default. The target for the mean debt to (annual) GDP ratio consists of the average public external debt between 1993 and 2001.

\section{Results}

Tables 4 and 5 report moments in the simulations of the benchmark model for each parametrization. Following Pouzo and Presno (2016), we report results for pre-default simulation samples, except for the computation of default frequencies which are computed on the entire sample. We simulate the model for a number of periods that allows us to extract 1000 samples of 35 consecutive periods before a default. We focus on samples of 35 periods because we compare the artificial data generated by the model with Argentine data from the first quarter of 1993 to the last quarter of $2001{ }^{20}$ In order to facilitate the comparison of simulation results with the data, we only consider simulation sample paths in which the last default was declared at least four periods before the beginning of each sample. Default frequencies are computed using all simulation data.

Table 4 shows the simulation results of the benchmark model (column "Noncontingent") un-

\footnotetext{
${ }^{19}$ This frequency is often used in previous studies (see, for example, Arellano, 2008 or Aguiar and Gopinath, 2006).

${ }^{20}$ The qualitative features of this data are also observed in other sample periods and in other emerging markets (see, for example, Aguiar and Gopinath, 2007, Alvarez et al., 2011, Boz et al., 2011, Neumeyer and Perri, 2005, and Uribe and Yue, 2006).
} 
der the Chatterjee and Eyigungor (2012) parametrization described above. It also shows how the simulation results change in this case if we introduce robust lenders with the value of $\theta$ calibrated by Pouzo and Presno (2016). Analogously, Table 5 shows the simulation results of the benchmark model (column Noncontingent) under the Pouzo and Presno (2016) parametrization in Table 3. It also shows how the simulation results change in this case if we consider rational expectations lenders as in Chatterjee and Eyigungor (2012). Overall, the tables show that both benchmark calibrations match the data reasonably well. As in the data, in the simulations of the baseline model, consumption and income are highly correlated and the spread is countercyclical. Consumption volatility is higher than income volatility, which is consistent with the findings in Neumeyer and Perri (2005) and Aguiar and Gopinath (2007). The calibrations closely match the targeted moments. The crucial difference is that only with robust lenders the model is able to match simultaneosuly the moments of the spread and default frequency in the data, which is the main contribution from Pouzo and Presno (2016). Chatterjee and Eyigungor (2012) is able to match the mean spread level but at the expense of a much larger default probability. Pouzo and Presno (2016) show that the model with robust lenders is also able to match other quantiles of spread in the data.

Table 4: Statistics based on Chatterjee and Eyigungor (2012)

\begin{tabular}{lcccccccc}
\hline & \multicolumn{3}{c}{ Rational Expectations (benchmark) } & & \multicolumn{3}{c}{$\theta=1.6155$} \\
\cline { 2 - 3 } Statistic & Noncontingent & Threshold & $\alpha=1$ & & Noncontingent & Threshold & $\alpha=1$ \\
\hline Spread & 8.5 & 0.6 & 6.8 & & 8.4 & 15.5 & 7.1 \\
Std Spread & 4.3 & 0.4 & 3.0 & & 4.4 & 2.3 & 3.1 \\
Debt & 69.9 & 159.6 & 74.4 & & 62.6 & 87.7 & 67.2 \\
Std(c)/Std(y) & 1.24 & 0.83 & 1.21 & & 1.25 & 0.82 & 1.22 \\
Corr(y,c) & 0.98 & 0.53 & 0.98 & & 0.98 & 0.94 & 0.98 \\
Corr(y,tb/y) & -0.7 & 0.52 & -0.62 & & -0.67 & 0.58 & -0.6 \\
Corr(y,spread) & -0.77 & -0.87 & -0.78 & & -0.75 & -0.61 & -0.77 \\
Default Prob & 5.8 & 0.56 & 5.3 & & 2.3 & 0.12 & 1.8 \\
Welfare Gains & - & 1.86 & 0.27 & - & -0.87 & 0.2 \\
\hline
\end{tabular}

Note: Threshold debt pays if income is above the mean and payments are linearly indexed with alpha $=1$.

Next, we turn to the analysis of allowing the government to issue state-contingent debt. In 
Table 5: Statistics based on Pouzo and Presno (2016)

\begin{tabular}{lcccccccc}
\hline & \multicolumn{3}{c}{ Rational Expectations } & & \multicolumn{3}{c}{$\theta=1.6155$ (benchmark) } \\
\cline { 2 - 3 } Statistic & Noncontingent & Threshold & $\alpha=1$ & & Noncontingent & Threshold & $\alpha=1$ \\
\hline Spread & 8.1 & 0.36 & 7.2 & & 8.15 & 11.1 & 7.1 \\
Std Spread & 4.5 & 0.23 & 3.7 & & 4.6 & 1.58 & 3.6 \\
Debt & 48.7 & 116.5 & 50.8 & & 44.0 & 67.6 & 46.1 \\
Std(c)/Std(y) & 1.24 & 0.82 & 1.22 & & 1.25 & 0.84 & 1.23 \\
Corr(y,c) & 0.98 & 0.55 & 0.98 & & 0.98 & 0.93 & 0.98 \\
Corr(y,tb/y) & -0.71 & 0.54 & -0.67 & & -0.68 & 0.52 & -0.64 \\
Corr(y,spread) & -0.77 & -0.87 & -0.79 & & -0.76 & -0.63 & -0.77 \\
Default Prob & 5.5 & 0.3 & 5.3 & & 3.0 & 0.0 & 2.6 \\
Welfare Gains & - & 1.19 & 0.09 & - & -0.37 & 0.07 \\
\hline
\end{tabular}

Note: Threshold debt pays if income is above the mean and payments are linearly indexed with alpha $=1$.

both tables, the column "Threshold" shows the simulation results when the government can issue an income-indexed bond with parameters $\tau=\bar{y}$ and $\alpha=1$. This bond structure in the model intends to capture the GDP-linked bond that Argentina issued in 2005 (the details of this bond are discussed in Section 3). Tables 4 and 5 show that the qualitative results from the two-period model carry over into the quantitative model. Under both parametrizations, this income-indexed bond generates substantial welfare gains if the small-open economy faces rational expectations lenders. As the government does not need to make coupon payments in any income realization lower to the mean, the default probability and, thus, the spread are almost eliminated. This allows the government to increase its indebtedness and reduce the volatility of consumption. The threshold bond effectively expands the government borrowing opportunities (larger indebtedness at more favorable prices).

However, when the government faces robust lenders, under both parametrizations the government is made worse off by the introduction of the threshold bond. In these cases, while the threshold bond still reduces the volatility of consumption relative to income and eliminates most of the default risk, it still leads to a large increase in bond spreads. The sovereign spread increases from 8.5 to 15.5 percent in the Chatterjee and Eyigungor (2012) calibration, and from 8.15 to 11.1 percent in the Pouzo and Presno (2016) calibration. From the discussion in Section 3, with robust 
lenders the sovereign spread not only reflects the default premium but also includes the amiguity premia (from default and contingency). Given that the government never defaults with this bond structure, the default premium and the ambiguity premium associated with default are both zero. But, robust lenders' probability distortions amplify the likelihood of states in which the bond promises no repayment. This leads to a large ambiguity premium related to the contingency of the bond which explains the resulting levels of the spread and, ultimately, the associated welfare losses. Consistent with the results from the two-period model, these findings show that, through the lens of our model, the unexplained portion of the spread of the Argentinian GDP-linked bond that the literature has labeled as a novelty premium (Costa, Chamon, and Ricci, 2008) is in fact an ambiguity premium. Moreover, the welfare losses could also rationalize why countries have not issued these bonds more frequently in practice.

Finally, we search for the optimal state-contingent bond design. For each calibration, we maximize the welfare of the sovereign by choosing the parameter values $\tau$ and $\alpha$. Table 6 shows the simulation results. We find that the optimal bond design depends on the type of lenders the government is facing. In particular, while the threshold level $\tau$ is similar within each calibration, the optimal degree of indexation $\alpha$ is lower when lenders feature preferences for robustness. In all cases, the optimal state-contingent bond substantialy reduces both default risk and the volatility of consumption. At the same time, this allows the government to increase its indebtedness. When lenders have rational expectations, the decline in default risk implies a similar reduction in the sovereign spread. However, when lenders are robust the sovereign spread remains around 3\% even with negligible default risk. As discussed in Section 3, this spread level is due to the ambiguity premium related to the contingency of the bond. Overall, choosing the optimal statecontingent bond design results in large welfare gains, although these are larger with rational expectations lenders. ${ }^{21}$

\footnotetext{
${ }^{21} \mathrm{We}$ also find that for a given state-contingent structure, welfare gains are decreasing in the robustness parameter $\theta$.
} 
Table 6: Statistics based on Chatterjee and Eyigungor (2012) and Pouzo and Presno (2016) under the optimal state-contingent bond with and without robust lenders.

\begin{tabular}{|c|c|c|c|c|}
\hline \multirow[b]{2}{*}{ Statistic } & \multicolumn{2}{|c|}{ Chatterjee and Eyigungor (2012) } & \multicolumn{2}{|c|}{ Pouzo and Presno (2016) } \\
\hline & $\begin{array}{c}\text { Rational Expectations } \\
\tau=0.75, \alpha=4\end{array}$ & $\begin{array}{l}\text { Robustness } \\
\tau=0.8, \alpha=3\end{array}$ & $\begin{array}{c}\text { Rational Expectations } \\
\tau=0.875, \alpha=7\end{array}$ & $\begin{array}{c}\text { Robustness } \\
\tau=0.875, \alpha=5\end{array}$ \\
\hline Spread & 0.02 & 2.83 & 0.1 & 2.8 \\
\hline Std Spread & 0.02 & 0.11 & 0.04 & 0.13 \\
\hline Debt & 119.8 & 95.7 & 79.3 & 65.9 \\
\hline $\operatorname{Std}(\mathrm{c}) / \operatorname{Std}(\mathrm{y})$ & 0.8 & 0.99 & 0.76 & 0.96 \\
\hline $\operatorname{Corr}(\mathrm{y}, \mathrm{c})$ & 0.99 & 0.98 & 0.99 & 0.98 \\
\hline $\operatorname{Corr}(\mathrm{y}, \mathrm{tb} / \mathrm{y})$ & 0.98 & 0.13 & 0.98 & 0.25 \\
\hline Corr(y,spread) & -0.42 & -0.17 & -0.91 & -0.67 \\
\hline Default Prob & 0.04 & 0.17 & 0.1 & 0.23 \\
\hline Welfare Gains & 3.2 & 1.44 & 1.79 & 0.79 \\
\hline
\end{tabular}

\section{Conclusion}

This paper studies why countries have issued sovereign state-contingent bonds only on a modest scale and these have traded at a large discount, despite the well-known benefits typically discussed in the literature. We rationalize these facts in the context of a standard sovereign default model à la Eaton and Gersovitz (1981) with long-term debt in which foreign investors have concerns about model misspecification. International lenders are ambiguity averse and guard themselves against possible misspecification errors in their approximating model by choosing the worst within some specified set of plausible income processes. While state-contingent debt is effective in reducing default risk, robust lenders distort probabilities by assigning higher likelihood to those states where the bond promises lower repayments, resulting in an ambiguity premium associated with the contingency of the bond.

We show that this ambiguity premium can be very large when state-contingent bonds feature the threshold structure observed in recent issuances by emerging markets (e.g., Argentina's 2005 GDP warrant), which results in substantial welfare losses. This bond structure, embedded in our model of robust international lenders, can account for the little use of these financial instruments and their unfavorable pricing. However, even this 'threshold' bond generates welfare gains when 
facing rational-expectations lenders. In this regard, we also show how the optimal bond design crucially depends on the degree of the lenders' preference for robustness. Moreover, the welfare gains from issuing optimally-designed state-contingent debt are decreasing in the level of robustness.

The optimal design of state-contingent debt with robust lenders balances several forces. Lenders charge premia for ambiguity related to the stipulated payments (ex-ante contingency) as well as for ambiguity related to default (ex-post contingency). As defaulting is costly, the optimal design uses ex-ante contingency to eliminate the probability of default ex-post. When lenders have an extreme degree of robustness, the government designs a bond that eliminates as much contingency as possible. In intermediate cases, the optimal structures enables some probability distortions in order to provide risk-sharing. The results of our calibration exercise generally support a state-contingent structure with linear indexation and potentially a threshold to cover against the extreme left tail of shocks to income. 


\section{References}

Adam, K. and Woodford, M. (2012). 'Robustly optimal monetary policy in a microfounded New Keynesian model'. Journal of Monetary Economics, volume 59 (5), 468-487.

Aguiar, M., Chatterjee, S., Cole, H., and Stangebye, Z. (2016). 'Quantitative Models of Sovereign Debt Crises'. Handbook of Macroeconomics, volume 2B, 1697-1755. Chapter 21.

Aguiar, M. and Gopinath, G. (2006). 'Defaultable debt, interest rates and the current account'. Journal of International Economics, volume 69, 64-83.

Aguiar, M. and Gopinath, G. (2007). 'Emerging markets business cycles: the cycle is the trend'. Journal of Political Economy, volume 115, no. 1, 69-102.

Alvarez, F. A., Marques, L. B., and Toledo, M. (2011). 'Business Cycles in Emerging Markets: The Role of Durable Goods and Financial Frictions'. Manuscript, Universidad Carlos III.

Arellano, C. (2008). 'Default Risk and Income Fluctuations in Emerging Economies'. American Economic Review, volume 98(3), 690-712.

Arellano, C. and Ramanarayanan, A. (2012). 'Default and the Maturity Structure in Sovereign Bonds'. Journal of Political Economy, volume 120, no. 2, 187-232.

Backus, D., Kehoe, P., and Kydland, F. (1992). 'International real business cycles'. Fournal of Political Economy, volume 100 (4).

Benford, J., Ostry, J. D., and Shiller, R. (2018). Sovereign GDP-Linked Bonds: Rationale and Design. A VoxEU.org eBook, London: CEPR Press.

Beraja, M. (2020). 'A Semi-structural Methodology for Policy Counterfactuals'. Mimeo.

Bertinatto, L., Gomtsyan, D., Sandleris, G., Sapriza, H., and Taddei, F. (2017). 'Indexed Sovereign Debt: An Applied Framework'. Mimeo. 
Bidder, R. and Smith, M. (2012). 'Robust Animal Spirits'. Journal of Monetary Economics, volume 59 (8), 738-750.

Borensztein, E. and Mauro, P. (2004). 'GDP-indexed bonds'. Economic Policy, pages 165-216.

Boz, E., Daude, C., and Durdu, B. (2011). 'Emerging Market Business Cycles Revisited: Learning about the Trend'. Fournal of Monetary Economics, volume 58, 616-631.

Chatterjee, S. and Eyigungor, B. (2012). 'Maturity, Indebtedness, and Default Risk'. American Economic Review, volume 102, no. 6, 2674-99.

Costa, A., Chamon, M., and Ricci, L. (2008). 'Is There a Novelty Premium on New Financial Instruments? The Argentine Experience with GDP-Indexed Warrants'. IMF Working Papers 08/109, International Monetary Fund.

D’Erasmo, P., Mendoza, E., and Zhang, J. (2016). 'Quantitative Models of Sovereign Debt Crises'. Handbook of Macroeconomics, volume 2B, 2493-2597. Chapter 32.

Durdu, B. (2009). 'Quantitative implications of indexed bonds in small open economies'. Fournal of Economic Dynamics \& Control, volume 33, 883-902.

Eaton, J. and Gersovitz, M. (1981). 'Debt with potential repudiation: theoretical and empirical analysis'. Review of Economic Studies, volume 48, 289-309.

Farhi, E. and Werning, I. (2017). 'Fiscal Unions'. American Economic Review, volume 107 (12), $3788-3834$.

Hansen, L. P. and Sargent, T. J. (2001). 'Robust Control and Model Uncertainty'. American Economic Review, volume 91, no. 2, 60-66.

Hansen, L. P. and Sargent, T. J. (2016). Robustness. Princeton University Press. ISBN 9780691170978. 
Hatchondo, J. C. and Martinez, L. (2009). 'Long-duration bonds and sovereign defaults'. Journal of International Economics, volume 79, 117-125.

Hatchondo, J. C. and Martinez, L. (2012). 'On the Benefits of GDP-Indexed Government Debt: Lessons from a Model of Sovereign Defaults'. Economic Quarterly, volume 98, 139-157. No. 2.

Hatchondo, J. C., Martinez, L., and Sapriza, H. (2007). 'Quantitative Models of Sovereign Default and the Threat of Financial Exclusion'. Economic Quarterly, volume 93, 251-286. No. 3.

IMF (2017). 'State-Contingent Debt Instruments for Sovereigns'. IMF Policy Paper.

IMF (2020). 'The Role of State-Contingent Debt Instruments in Sovereign Debt Restructurings'. Staff discussion notes, International Monetary Fund.

Krugman, P. (1988). 'Financing vs. forgiving a debt overhang'. Journal of Development Economics, volume 29 (3), 253-268.

Moretti, M. (2020). 'Financial Innovation and Liquidity Premia in Sovereign Markets: The Case of GDP-Linked Bonds'. Mimeo.

Neumeyer, P. and Perri, F. (2005). 'Business cycles in emerging economies: the role of interest rates'. Journal of Monetary Economics, volume 52, 345-380.

Pina, G. (2020). 'State-Contingent Sovereign Bonds: A new database'. mimeo.

Pouzo, D. and Presno, I. (2016). 'Sovereign Default Risk and Uncertainty Premia'. American Economic fournal: Macroeconomics, volume 8, no. 3, 230-66.

United Nations (2006). 'GDP-Indexed Bonds: Making It Happen’. Economic \& Social Affairs, United Nations.

Uribe, M. and Yue, V. (2006). 'Country spreads and emerging countries: Who drives whom?' Journal of International Economics, volume 69, 6-36. 